\title{
Experimental Study on Shear Property of Integrated Sandwich Panel of Aluminum Honeycomb and Epoxy Resin
}

\author{
Xin Yajun, Zhao Xuya, Liu Xiaoman, Tie Rui and Cheng Shuliang* \\ Key Laboratory of Mechanical Reliability for Heavy Equipments and Large Structures of Hebei Province, Yanshan Uni- \\ versity, Qinhuangdao, 066004, China
}

\begin{abstract}
In order to realize functional integration, a new kind of sandwich panel was made. By carrying out quasi-static shear experiments, its elastic modulus and ultimate bearing capacity with different resin immersing thickness, additional layer thickness of resin and specimen thickness were investigated. The load - displacement curves and failure models were obtained, which were compared with the traditional aluminum honeycomb sandwich panel. The experiments indicated that the integrated aluminum honeycomb and epoxy resin sandwich panel's shearing process undergoes three phases: elasticity, yield and destruction. The specimen's elastic modulus and ultimate bearing capacity increase with the increase of the resin thickness, additional layer thickness of resin and the specimen thickness, which greatly improve compared to the traditional sandwich structure. The composite layer and the core show good stability under shearing process, and there is no peeling-off or cracking between the composite layer and the core.
\end{abstract}

Keywords: Aluminum honeycomb, Epoxy resin, Sandwich panel, Integral whole, Shear test, Composite layer.

\section{INTRODUCTION}

Honeycomb material is a great research in major human bionics, which was inspired by natural hexagonal honeycomb. Scientists have discovered that compared with other shapes, it could get the biggest volume and stiffness if the same amount of material was made into the shape of honeycomb [1]. Since the continuous multi-wall arrangement of the honeycomb and hexagonal network structure, disperse the external force from all directions, the extrusion resistance of the honeycomb structure is much higher than other shapes [2], thus aluminum honeycomb sandwich panel with aluminum honeycomb core has been developed. The aluminum honeycomb material has a special porous structure. As a result, it is becoming widely used in the field of damping and energy absorption such as metallurgy, chemical, aerospace, shipping, electronics, automotive manufacturing, architecture and so on [3-5]. Sandwich panel combined with aluminum honeycomb and other metal panel has become a hot spot research direction in the academic circle for its lightweight, high specific stiffness, etc. [6-9]. Traditional preparation methods of aluminum honeycomb sandwich panel are bonding and welding [10-12]. However, with its low bond strength and poor performance at high temperatures or corrosive conditions, the bonding method can easily cause stripping of the core and the surface; while the welding method combines welding flux and aluminum together that may cause corrosion. While a drawback is that the welding area is only limited to the aperture that also decreases the structural strength [11].

\footnotetext{
*Address correspondence to this author at the Key Laboratory of Mechanical Reliability for Heavy Equipments and Large Structures of Hebei Provice, Yanshan University, Qinhuangdao, 066004, China; E-mail: slcheng@ysu.edu.cn
}

In recent years, the mechanical properties of different types of aluminum honeycomb sandwich panels have been widely concentrated on and studied by scholars at home and abroad. Zhou Zhulin [13] conducted shear tests of aluminum honeycomb sandwich panel under different boundary conditions and found that experimental results and theoretical values of the shear strength are very consistent. Ashby [14] drew a collapse mechanism diagram of sandwich beam, and analyzed the failure modes of sandwich panel under the condition of four-point bending. Through shear tests and finite element method, Pan [15] studied the transverse shear modulus and strength of No.5056 aluminum honeycomb core. Russell [16] conducted a three-point bending test on carbon fiber honeycomb sandwich beams. Core shear, core indentation, panel micro-buckling and panel folds failure modes were also obtained.

Aluminum honeycomb core mainly withstands shear force and surface layer mainly withstands bending force. Therefore, it is important to study the bending and shear properties of aluminum honeycomb sandwich panel [17]. A kind of integrated composite sandwich panel is proposed. The upper and lower surfaces of the structure are aluminumresin composite layers, and the core is aluminum honeycomb. This composite sandwich panel's core and surface layers are connected to a whole without any obvious interface. The overall performance is greatly improved. By quasishear experiments, the integrated aluminum honeycomb sandwich panel's mechanical properties were tested and the influence of different resin immersing thickness, additional layer thickness of resin and specimen thickness on its mechanical properties were analyzed. Also it is compared with traditional aluminum honeycomb sandwich panel which was made by paste methods. 


\section{EXPERIMENT}

\subsection{The Experimental Material}

Hexagon aluminum honeycomb was chosen as the main material, which has the advantage of good flatness, high strength, low density and high ability of shear. The thickness of the cell is $0.05 \mathrm{~mm}$. The DY.E.44 resin and DY.EP resin firming agent were selected, both of which are produced by Norsun Chemical Limited Company. In order to improve the plastic and mechanical properties of composite material, dibutyl phthalate was chosen as plasticizer.

\subsection{Manufacture of the Specimens}

First, according to the test purpose, core material with different pore size and core thickness is made into 140 $\mathrm{mm} \times 40 \mathrm{~mm}$ specifications, and the grease is washed away from aluminum honeycomb with alcohol. Then they are put in a ventilated place to make them dry naturally. Second, groove molds are made to make aluminum honeycomb pan$\mathrm{el}$, and the height of the mold is same with the height of resin immersed in the panel. Third, the resin and firming agent are put in a water bath and the water is kept heating at $60^{\circ} \mathrm{C}$. If the temperature is too high, the reaction rate would be so fast that no bubbles would come out. If too low, the flow ability would be poor which makes it difficult to stir. Fourth, stop heating when both of them have a good liquidity, in a beaker they are mixed at the ratio of $1: 1$, and $5 \%$ of the plasticizer is added and stir rapidly until the polymer is color uniformed and bubble free. Fifth, they are fully filled into the mold which has a specific thickness, and shave. The depth of mold is the sum thickness of immersed and additional resin layer. Some supports are pasted to the bottom of core material, and the thickness of the support is equal to the additional layer thickness of resin. Then the treated aluminum honeycomb sandwich panels are put into the molds slowly and smoothly, panels are immersed fully by the resin from the bottom of the aluminum honeycomb. Sixth, panels are solidified for three days at room temperature and then the molds and the excess resin at the edge of the aluminum honeycomb are removed. Seventh, the other side is poured into the resin by the same procedure. Finally, all the specimens are marked the number.

Table 1. Specimen number and parameter
Fig. (1) is the Schematic diagram of the integrated sandwich panel aluminum honeycomb and epoxy resin. Fig. (2) is test specimen pictures. Eight groups of specimens with different immersed resin thickness, additional layer thickness of resin and specimen thickness were designed. Specimen number and parameters are shown in Table $\mathbf{1}$.

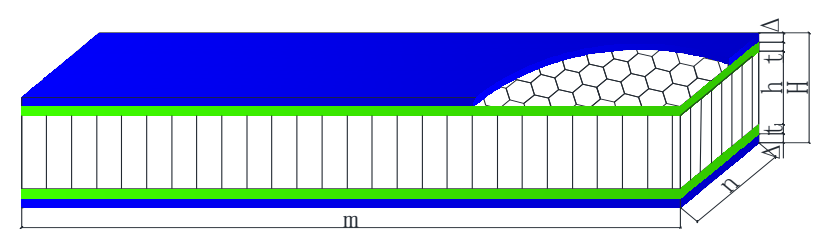

Notes: $H$ is the specimen's height, $\Delta$ is the additional layer thickness, $t$ is the immersed resin thickness, $h$ is the core's thickness, $m$ and $n$ are the lengths of specimen edge.

Fig. (1). Schematic diagram of the specimen.

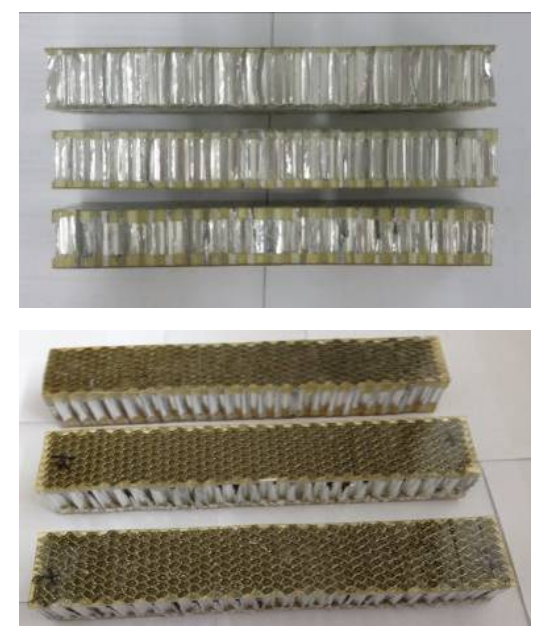

Fig. (2). Test specimen pictures.

\subsection{The Experimental Equipment and Load}

The tests on the specimen are conducted with the WDW3100 micro-controlled electronic universal testing machine which is produced by Changchun Kexin Test Instrument Co. Ltd. The specimen was sheared and loaded vertically at the speed of $1 \mathrm{~mm} / \mathrm{min}$, as in Fig. (3). Fourpoint shear test was conducted with the reference of Adams [18] described one. The schematic diagram of a four-point

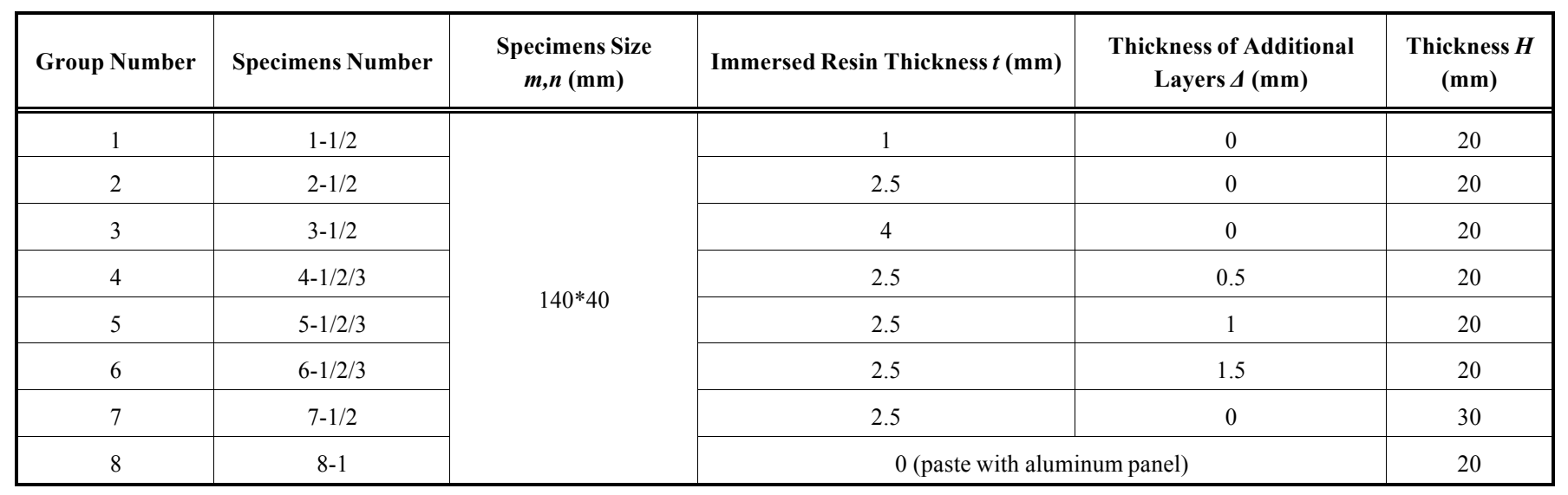


shear test method is shown in Fig. (4). The test data are all collected automatically by the computer.
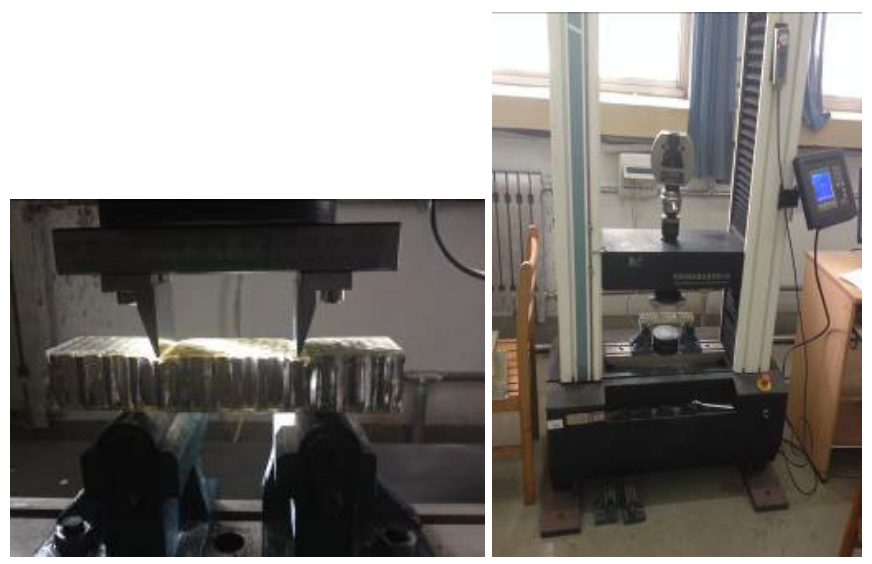

Fig. (3). Shear test pictures.

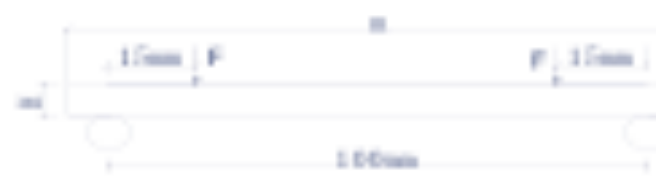

Fig. (4). Schematic diagram of test method.

\section{TEST RESULTS AND ANALYSIS}

\subsection{Process of Destruction}

The destructive process of shear test is shown in Fig. (5). Integrated sandwich panel of aluminum honeycomb and resin epoxy does not appear instability phenomena in the shearing process, which indicates that the specimen shows no obvious catastrophic changes in the loading process. In the process of destruction, the upper composite layer starts to appear micro-deformation at the load point. Then the upper composite layer and core appear depression while the lower composite layer appears cracking. Cracks develop to aluminum honeycomb core with the increase of load. However, because of the high stiffness of the composite layer, aluminum honeycomb core around cracks is also compressed with the increase of load until the specimen is destructed.

\subsection{Specimen Without Additional layer}

Group 1 to group 3 are specimens without additional layer. The quasi-static shear force-displacement curves of integrated sandwich panel of aluminum honeycomb and epoxy resin with different immersed resin thickness are shown in Fig. (6). It can be figured out that the integrated sandwich panel of aluminum honeycomb and epoxy resin undergoes two phases: elasticity and destruction. Elasticity (O-A): sandwich panel presents linear elastic deformation in the elastic range. Destruction (A-B): cracks appear in composite layer and core. The load bearing capacity of sandwich panel reduce rapidly once the load is beyond the yield load of aluminum honeycomb material. These three groups appear almost the same features except the load of group 1 has a small reduction during the elasticity phase. When immersed resin thickness is $1 \mathrm{~mm}$ in group 1, it is easy to appear small crack or deformation in the thin upper composite layer, as is shown in Fig. (6a). This disadvantage can be solved when compo- site layer thickness is thicker than $1 \mathrm{~mm}$, as is shown in Fig. $(\mathbf{6 b}, \mathbf{c})$.

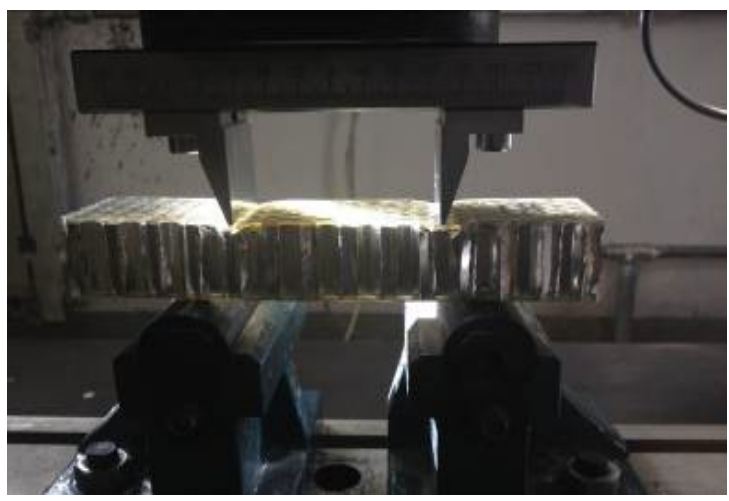

(a)

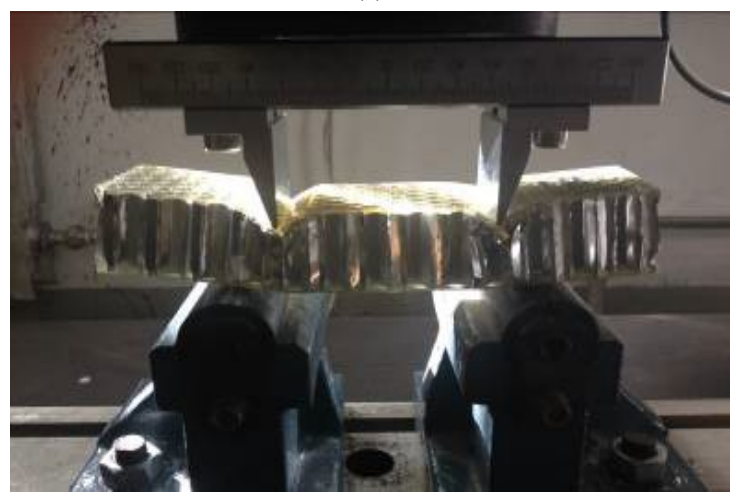

(b)

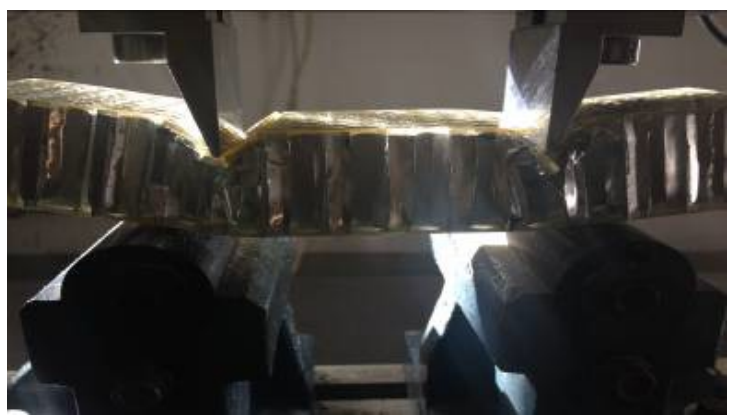

(c)

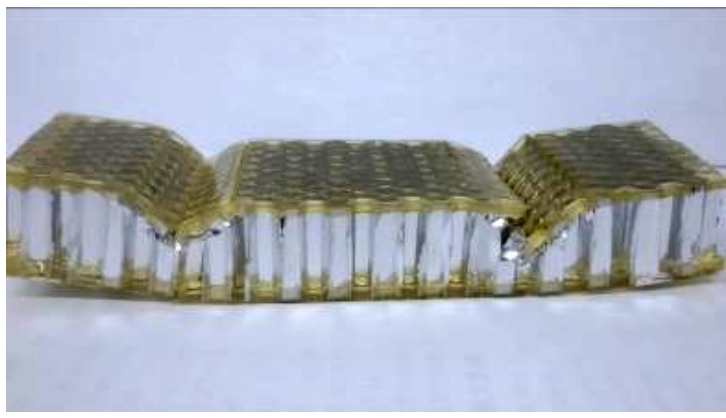

(d)

Fig. (5). Destruction form of the specimens.

The stiffness of specimen increases with the increase of immersed resin thickness. Thus the shear modulus and shear bearing capacity also increase gradually. With the increasing immersed resin thickness, the core gets thinner. The core bears load directly after the destruction of the composite layer, which results in the decrease of plastic and ener- 
gy consumption in the process of destruction. That's to say it will destroy more quickly.

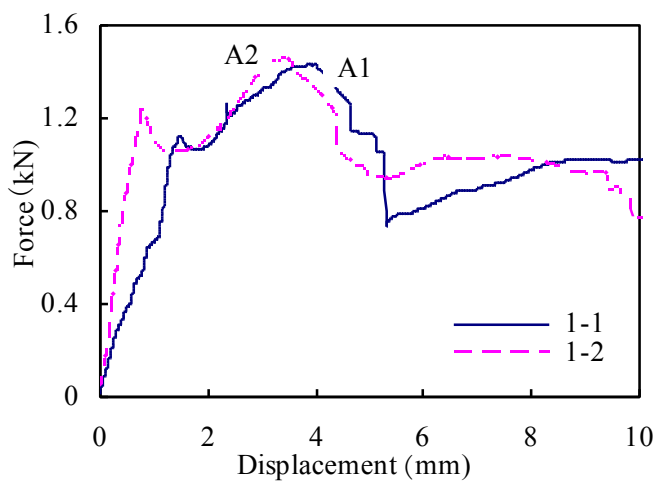

(a) The first group $t=1 \mathrm{~mm}$

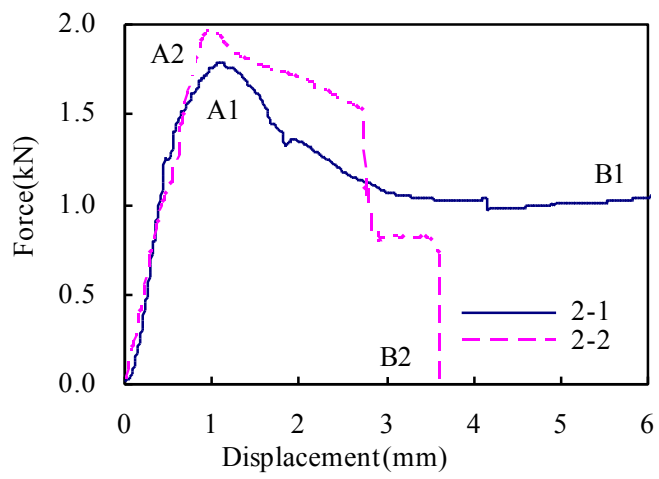

(b) The second group $t=2.5 \mathrm{~mm}$

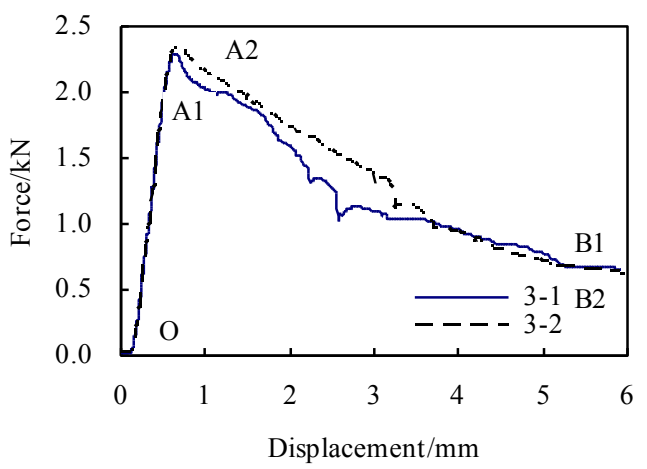

(c) The third group $t=4 \mathrm{~mm}$

Fig. (6). Force-displacement curves of specimens with different immersed resin thickness.

The average curves of the first, second and third group are compared, as is shown in Fig. (7).

It can be concluded from Fig. (7) that with the increase of immersed resin thickness, the stiffness of the upper and lower composite layers and ultimate bearing capacity of specimen have been greatly improved. In group 1 immersed resin thickness is $1 \mathrm{~mm}$, in group 2 the thickness is $2.5 \mathrm{~mm}$ and in group 3 the thickness is $4 \mathrm{~mm}$. It is found that the shear modulus of group 3 is 1.72 times larger than that of group 2 and 2.92 times than that of group 1. The ultimate bearing capacity of group 3 is 1.21 stronger than that of group 2 and 1.58 higher than that of group 1, as is shown in Fig. (8). Thus, with the increase of immersed resin thickness, the shear modulus and ultimate bearing capacity of specimens without additional layer increase gradually.

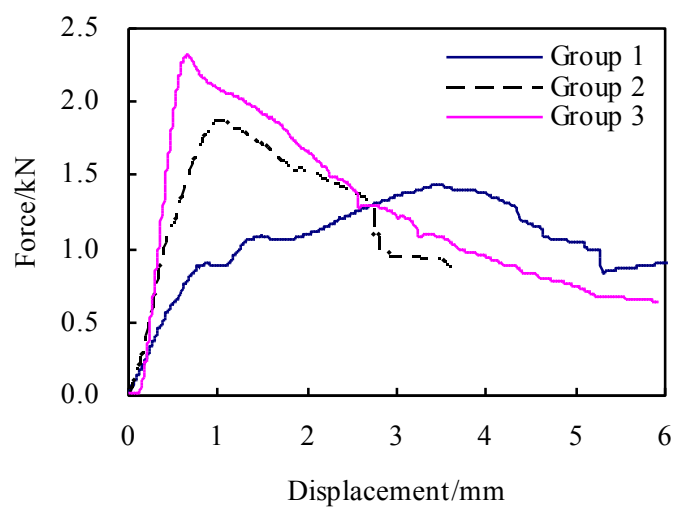

Fig. (7). The average force-displacement curves of first, second and third group specimen.

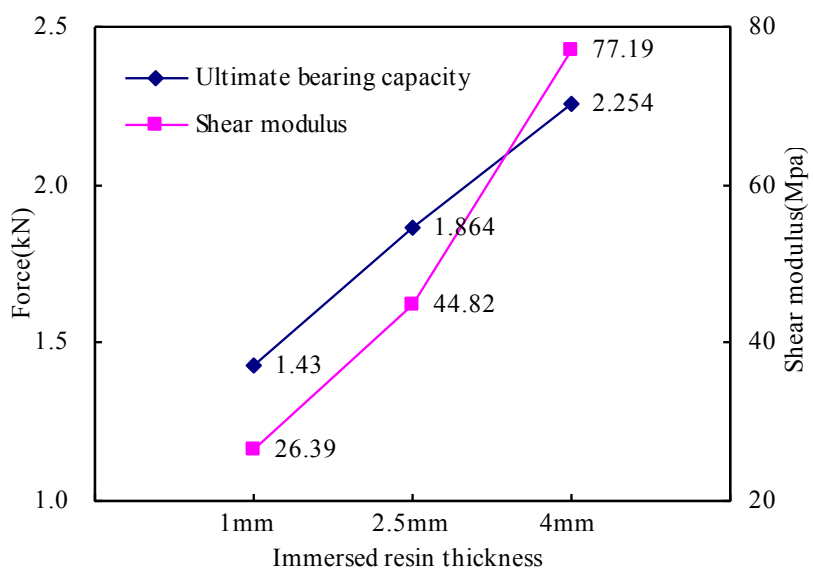

Fig. (8). The contrast curves of ultimate bearing capacity and shear modulus of specimen with different immersed resin thickness.

\subsection{Specimen with Additional Layer}

Fig. (9) is the force-displacement curves of the fourth, fifth and sixth groups of specimen, and the additional layer thickness are $0.5 \mathrm{~mm}, 1 \mathrm{~mm}$ and $1.5 \mathrm{~mm}$ respectively. It can be figured out that, different from the specimen without additional layer, specimen with additional layer undergoes three obvious phases: elasticity (O-A), yield (A-B) and destruction (B-C). The bearing capacity of the specimen appears to be a short-term decline after cracking in additional layer. With the destruction of the core, shear deformation begins. The material transforms the shearing released-energy into the needed-energy of deformation. Force-displacement curves appear platform stage until the core is damaged.

The average curves of the second, fourth, fifth and sixth group are compared, as in Fig. (10). It indicates that the shear modulus and ultimate bearing capacity of integrated sandwich panel of aluminum honeycomb and epoxy resin rise steadily with the increase of additional layer thickness. After comparing second, fourth, fifth and sixth group of specimens, it can be found that shear modulus of group 6 is 
1.41 times larger than that of group 5, 2.04 times than that of group 4 and 2.41 times than that of group 2 .

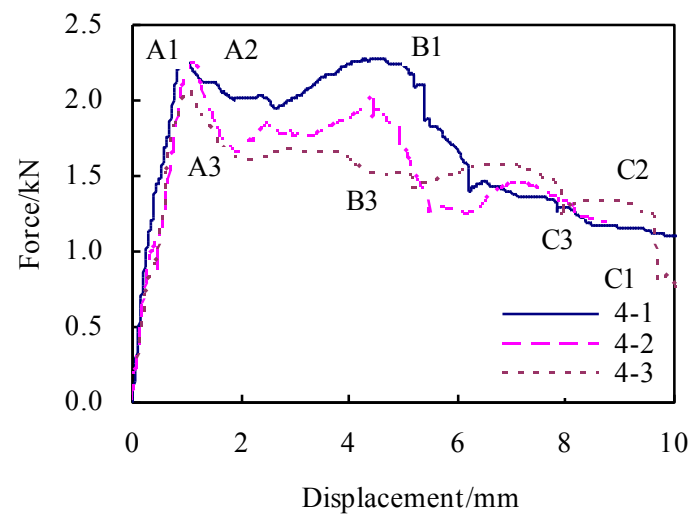

(a) The fourth group $\Delta=0.5 \mathrm{~mm}$

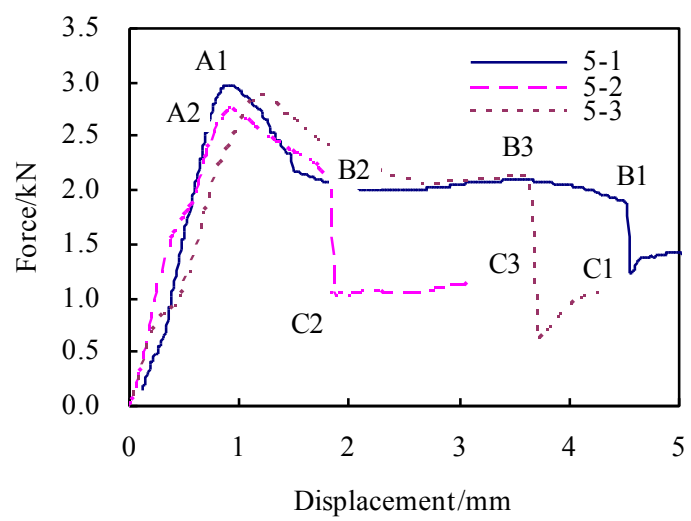

(b) The fifth group $\Delta=1 \mathrm{~mm}$

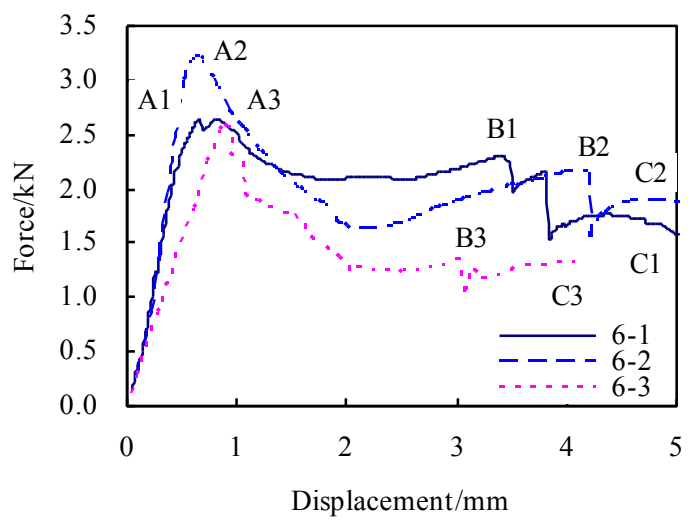

(c) The sixth group $\Delta=1.5 \mathrm{~mm}$

Fig. (9). Force-displacement curves of the fourth, fifth and sixth group specimens.

The ultimate bearing capacity of group 6 is 0.95 stronger than that of group 5, 1.23 higher than that of group 4 and 1.43 higher than that of group 2, as shown in Fig. (11). Thus, with the increase of additional layer thickness, the shear modulus and ultimate bearing capacity of specimen with additional layer increase gradually. Although the cores are cut from the same aluminum honeycomb panel, specific density of each specimen may vary due to the extrusion in the preservation process and aluminum honeycomb material's nature. This anomaly could explain the reason for the higher ultimate bearing capacity for group 5 .

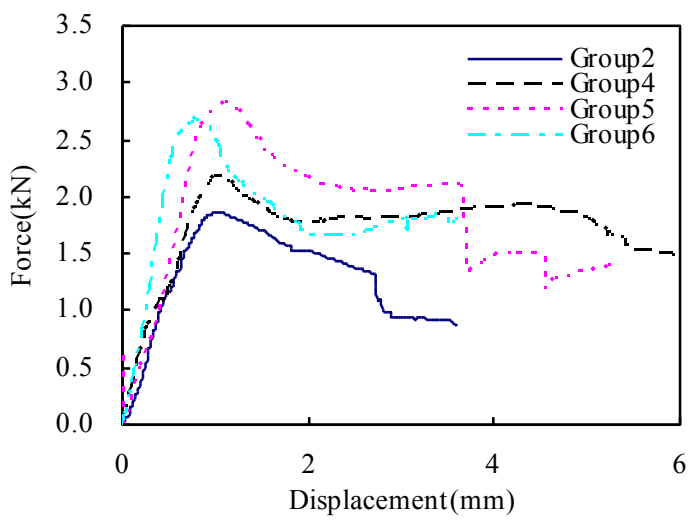

Fig. (10). Force-displacement curves of specimens with different additional layers' thickness.

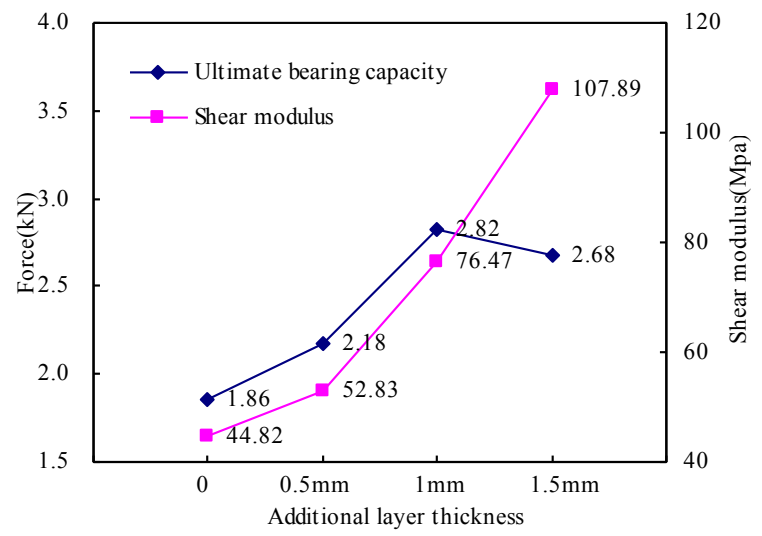

Fig. (11). Contrast curves of ultimate bearing capacity and shear modulus of specimens with different additional layer thickness.

\subsection{Influence of the Specimen Thickness}

Fig. (12) is the force-displacement curves of the seventh group specimen. The core thickness has increased with the increase of specimen thickness. The process of destruction is similar to those groups from 4 to 6 . What a difference is that the core's characteristic of damaging layer by layer improves the length of the yield platform greatly.

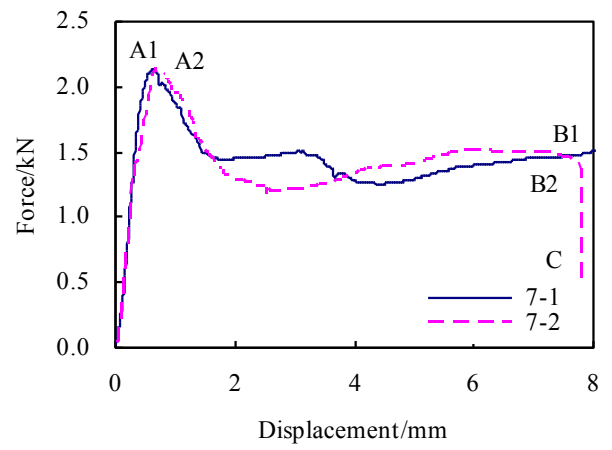

Fig. (12). Force-displacement curves of the seventh group of specimen. 


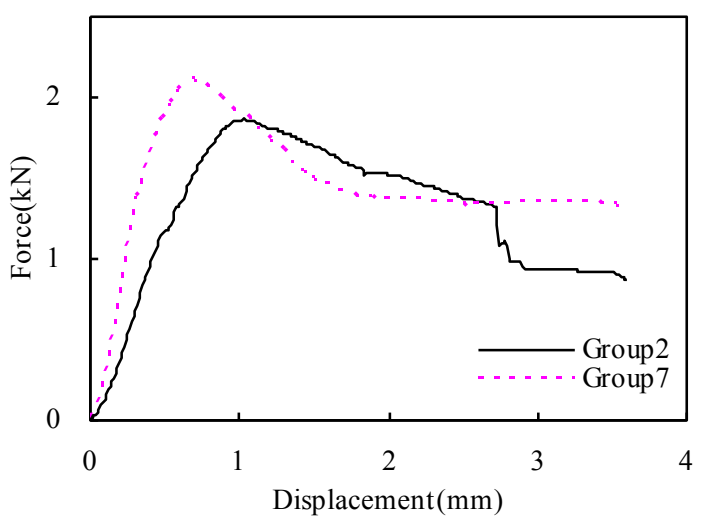

Fig. (13). Force-displacement curves of specimens with different thickness.

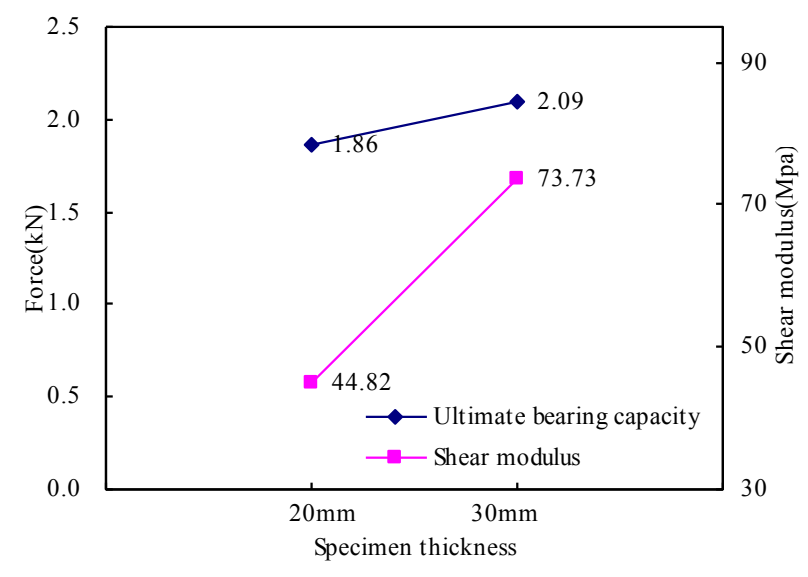

Fig. (14). Contrast curves of ultimate bearing capacity and shear modulus of specimens with different thickness.

The average curves of specimens in the second group (20 $\mathrm{mm}$ thickness) and the seventh group (30 mm thickness) are compared, as shown in Fig. (13). It can be concluded from Fig. (13) that with the increase of the specimen thickness, the yield load increases and the yield platform gets longer. The specimen thickness in group 7 is $30 \mathrm{~mm}$ and $20 \mathrm{~mm}$ in group 2. The shear modulus of group 7 is 1.65 times larger than that of group 2, the ultimate bearing capacity of group 7 is 1.12 stronger than that of group 2, as shown in Fig. (14). Thus, with the increase of specimen thickness, the specimen's shear modulus and ultimate bearing capacity increase gradually.

\subsection{Compared with Traditional Paste Aluminum Sand- wich Panel}

The surface aluminum panel of the aluminum honeycomb sandwich panel has good plasticity, which makes it deform together with aluminum honeycomb core without cracks under shearing process. The long yield phase also determines that the specimen has a good energy absorption capability.

The average curves of the second and eighth groups were compared, as shown in Fig. (15). It can be concluded that the shear modulus and ultimate bearing capacity of the integrat-

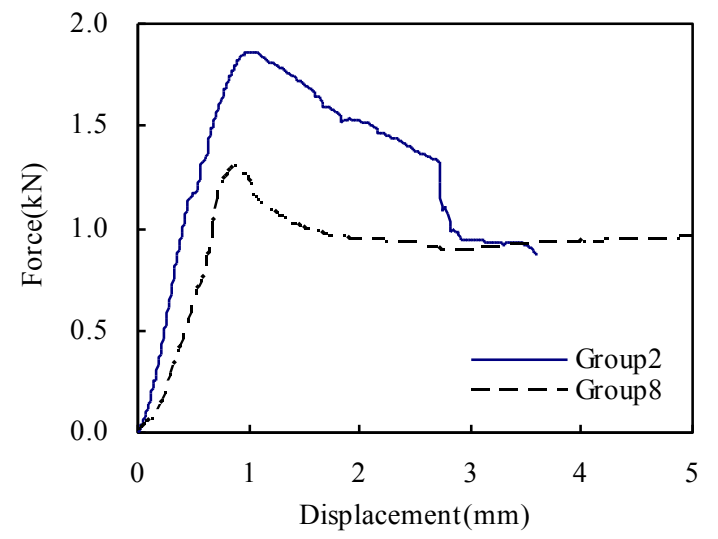

Fig. (15). Force-displacement curves of second and eighth group of specimens.

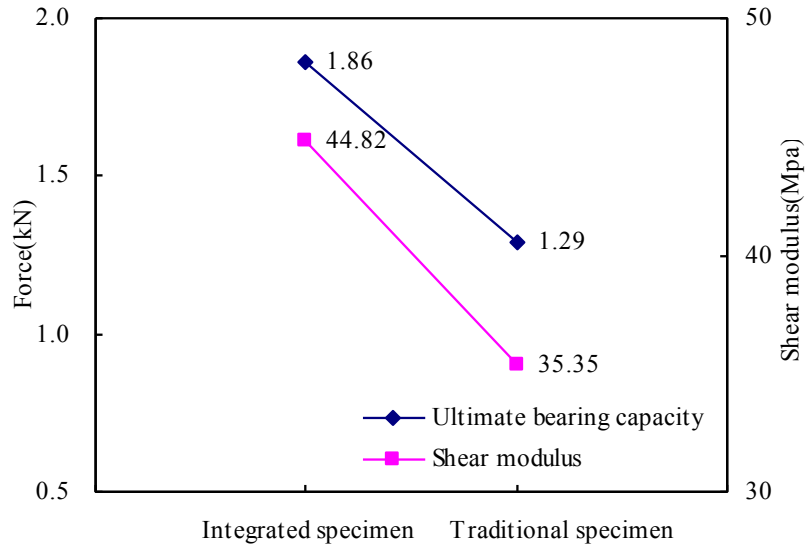

Fig. (16). Contrast curves of ultimate bearing capacity and shear modulus of integrated and traditional specimens.

ed sandwich panel of aluminum honeycomb and epoxy resin have been greatly improved compared with traditional sandwich panel. The shear modulus is 1.27 times larger than that of traditional sandwich panel and the ultimate bearing capacity is 1.45 times stronger, as shown in Fig. (16). Although the integrated sandwich panel occurs cracks under shearing process, the ultimate load capacity is still close to that of the traditional sandwich panel. Thus, the shear modulus and ultimate bearing capacity have been greatly improved than traditional sandwich panel.

\section{CONCLUSION}

1) The integrated sandwich panel of aluminum honeycomb and epoxy resin maintains good stability under shearing process, and there is no peeling-off or cracking between composite layer and core.

2) Under the condition of quasi-static shear, specimen without additional layer presents two phases: elasticity and destruction while specimen with additional layer presents three obvious phases: elasticity, yield and destruction. Specimens have a long yield platform and high ultimate bearing capacity. 
3) With the increase of the immersed resin thickness, the shear modulus and ultimate bearing capacity increase gradually. The ultimate bearing capacity and shear modulus of group 3 are 1.58 and 2.92 times respectively than that of group 1; With the increase of the additional layer thickness, the shear modulus and ultimate bearing capacity increase gradually. The ultimate bearing capacity and shear modulus of group 6 are 1.23 and 2.04 times respectively than that of group 4; With the increase of specimen thickness, the shear modulus and ultimate bearing capacity increase gradually. The ultimate bearing capacity and shear modulus of group 7 are 1.12 and 1.65 times respectively than that of group 2 .

4) The shear modulus and ultimate bearing capacity have been greatly improved than that of traditional sandwich panel.

\section{CONFLICT OF INTEREST}

The authors confirm that this article content has no conflict of interest.

\section{ACKNOWLEDGEMENTS}

The project was supported by Yanshan University Young Teachers Independent Research Fund, (No.15LGA011) and Qinhuangdao Science and Technology Fund (No. 201302A220), respectively.

\section{REFERENCES}

[1] J. Libiao, X. Cheng, L. Jinshui, "Researches on aluminum honeycomb sandwich material for noise control in coaches", Automobiles Pares, vol. 3, pp. 29-32, 2014.

[2] G. Wang, X. Li, "On the surface deformation measurement and energy absorption of a honeycomb panel subjected to low-velocity impact", Journal of Experimental Mechanics, vol. 26, pp. 573-581, 2011.

[3] L. Xin, Z. Peiwen, W. Zhihua, "Dynamic behavior of aluminum honeycomb sandwich panels under air blast: Experiment and nu- merical analysis", Composite Structures, vol. 108, pp. 1001-1008, 2014.

[4] R. Amnoiy, P. Varunee, "A study of energy saving in building through thermal insulation with plywood inserted honeycomb sandwich panels", Energy Procedia, vol. 34, pp. 964-972, 2013.

[5] L. Yongqiang, L. Feng, "Geometrically nonlinear forced vibrations of the symmetric rectangular honeycomb sandwich panels with completed clamped supported boundaries", Composite Structures, vol. 93, pp. 360-368, 2011.

[6] D. Yicheng, Y. Ning, “An experimental study of creep behavior of lightweight natural fiber-reinforced polymer composite/honeycomb core sandwich panels", Composite Structures, vol. 106, pp. 160$166,2013$.

[7] M.D. Theobald, G.S. Langdon, "Large inelastic response of unbonded metallic foam and honeycomb core sandwich panels to blast loading", Composite Structures, vol. 92, pp. 2465-2475, 2010

[8] V. Crupi, G. Epasto, "Collapse modes in aluminium honeycomb sandwich panels under bending and impact loading", International Journal of Impact Engineering, vol. 43, pp. 6-15, 2012.

[9] S. Sequeira Tavares, Y. Roulin, "Hybrid processing of thick skins for honeycomb sandwich structures", Composites Science and Technology, vol. 71, pp. 183-189, 2011.

[10] M. Wei, J. Zhang, "Introduction on composite sandwich panel fabrication", Applied Technology, vol. 25, pp. 50-57, 2004.

[11] M. Zhang, C. Chen, "Manufacturing technology of Al foam sandwich", Materials Review, vol. 22, pp. 85-89, 2008.

[12] L. Wu, S. Pan, "Survey of design and manufacturing of sandwich structures", Materials China, vol. 04, pp. 40-45, 2009.

[13] Z. Zhou, "The study on shear strength of honeycomb core", Fiber Composites, vol. 03, pp. 13-17, 1998.

[14] M.A. Ashby, A.G. Evans, "Fleck N A etc. Metal Foams: A Design Guide", Oxford: Butterworth Heinemann, 2000.

[15] S. Pan, L. Wu, Y. Sun, "Transverse shear modulus and strength of honeycomb cores", Composite Structures, vol. 84, pp. 369-374, 2008 .

[16] B.P. Russell, T. Liu, N.A. Fleck, "Quasi-static three-point bending of carbon fiber sandwich beams with square honeycomb cores", Journal of Applied Mechanics, vol. 78, pp. 1-15, 2011.

[17] Liu Jun. "Analysis of vibration and shock response of sandwich structures with square honeycomb core", Wu Han: Huazhong University of science and technology, 2004

[18] D.F. Adams, E.Q. Lewis, "Current status of composite material shear test methods", SAMPE Journal, vol. 31, pp. 32-41, 1995.

Received: May 26, 2015

Revised: July 14, 2015

Accepted: August 10, 2015

(C) Yajun et al.; Licensee Bentham Open.

This is an open access articles licensed under the terms of the Creative Commons Attribution-Non-Commercial 4.0 International Public License (CC BY-NC 4.0) (https://creativecommons.org/licenses/by-nc/4.0/legalcode), which permits unrestricted, non-commercial use, distribution and reproduction in any medium, provided that the work is properly cited. 